\title{
Sedation and Regional Anesthesia for Deep Brain Stimulation in Parkinson's Disease
}

\author{
Onur Ozlu, Sema Sanalbas, Dilek Yazicioglu, Gulten Utebey, and Ilkay Baran \\ Ankara Diskapi Yildirim Beyazit Teaching and Research Hospital, Irfan Bastug Caddesi, Dıskapı, 06330 Ankara, Turkey \\ Correspondence should be addressed to Dilek Yazicioglu; dilek.yazicioglu@hotmail.com
}

Received 7 September 2014; Revised 5 November 2014; Accepted 6 November 2014; Published 20 November 2014

Academic Editor: Kwok M. Ho

Copyright (C) 2014 Onur Ozlu et al. This is an open access article distributed under the Creative Commons Attribution License, which permits unrestricted use, distribution, and reproduction in any medium, provided the original work is properly cited.

Objective. To present the conscious sedation and the regional anesthesia technique, consisting of scalp block and superficial cervical plexus block, used in our institution for patients undergoing deep brain stimulation (DBS) for the treatment of Parkinson's disease (PD). Methods. The study included 26 consecutive patients. A standardized anesthesia protocol was used and clinical data were collected prospectively. Results. Conscious sedation and regional anesthesia were used in all cases. The dexmedetomidine loading dose was $1 \mu \mathrm{g} \mathrm{kg}^{-1}$ and mean infusion rate was $0.26 \mu \mathrm{g} \mathrm{kg}^{-1} \mathrm{~h}^{-1}(0.21)$ [mean total dexmedetomidine dose: 154.68 $\mu \mathrm{g}(64.65)$ ]. Propofol was used to facilitate regional anesthesia. Mean propofol dose was $1.68 \mathrm{mg} \mathrm{kg} \mathrm{(0.84)} \mathrm{[mean} \mathrm{total} \mathrm{propofol} \mathrm{dose:} 117.72 \mathrm{mg}$ (59.11)]. Scalp block and superficial cervical plexus block were used for regional anesthesia. Anesthesia related complications were minor. Postoperative pain was evaluated; mean visual analog scale pain scores were 0 at the postoperative 1st and 6th hours and 4 at the 12th and 24th hours. Values are mean (standard deviation). Conclusions. Dexmedetomidine sedation along with scalp block and SCPB provides good surgical conditions and pain relief and does not interfere with neurophysiologic testing during DBS for PD. During DBS the SCPB may be beneficial for patients with osteoarthritic cervical pain. This trial is registered with Clinical Trials Identifier NCT01789385.

\section{Introduction}

Deep brain stimulation (DBS) is used for the treatment of movement disorders in Parkinson's disease (PD) [1]. The procedure consists of the application of a stereotactic head frame, determination of target areas, and insertion of electrodes into certain deep brain structures and after neurophysiologic and clinical testing the connection of the electrodes to an implanted pacemaker $[1,2]$. Anesthesia is provided mainly by three techniques, local anesthesia, conscious sedationregional anesthesia, and general anesthesia $[1,2]$. A reliable conscious sedation technique should produce a state that the patient is sedated and remains responsive and cooperative to verbal commands and it should not interfere with neurophysiologic testing. The data considering the implications of anesthetics on neurophysiologic testing are inconclusive and intraoperative discomfort is still a problem during DBS [3].

As an institution using conscious sedation and regional anesthesia we aimed to report the anesthesia techniques used in our institution.

\section{Methods}

This study was performed in patients with PD scheduled for DBS. Ethical approval was obtained and all patients signed an informed consent to participate in this study. Data were collected prospectively. The conscious sedation and regional anesthesia procedures were explained to the patients by the responsible anesthetist. Dementia, obstructive sleep apnea, morbid obesity, gastroesophageal reflux, and difficult airway were the exclusion criteria. Age, gender, body mass index (BMI), ASA classification, and comorbid diseases were recorded.

2.1. Anesthesia Protocol. Premedication was not administered. Heart rate (HR) noninvasive blood pressure (systolic arterial pressure, SAP; diastolic arterial pressure, DAP; mean arterial pressure, MAP), peripheral oxygen saturation $\left(\mathrm{SpO}_{2}\right)$, respiratory rate (RR), body temperature, and bispectral index (BIS) were monitored. Urinary catheterization 
was not used. It was assured that all patients were in a comfortable position. Ringers lactate solution was infused at $50-100 \mathrm{~mL} \mathrm{~h}^{-1}$. All patients received oxygen $2 \mathrm{~L} \mathrm{~min}^{-1}$ via a nasal cannula. Nasal airway, laryngeal mask airway, and endotracheal tube were prepared as rescue airway devices. Respiratory depression was defined as $\mathrm{SpO}_{2}<92$ and $\mathrm{RR}$ $\leq 8$ breaths $\min ^{-1}$. Maneuvers needed to manipulate the airway patency were recorded. Hypertension ( $\geq 20 \%$ increase in MAP in comparison with baseline values) was treated with nitroglycerine or esmolol, hypotension ( $\geq 20 \%$ decrease in MAP in comparison with base line values) was treated with a fluid bolus and/or ephedrine $5 \mathrm{mg}$, bradycardia $(\mathrm{HR}<$ 50 beats $\mathrm{min}^{-1}$ ) was treated with atropine $0.5 \mathrm{mg}$, and tachycardia ( $\geq 20 \%$ increase in HR in comparison with baseline values) was treated with esmolol.

Initial sedation was employed with dexmedetomidine $1 \mu \mathrm{g} \mathrm{kg}^{-1}$ loading dose in 10 minutes, followed by $0.2-$ $0.8 \mu \mathrm{g} \mathrm{kg}^{-1} \mathrm{~h}^{-1}$ infusion. Propofol $(20 \mathrm{mg})$, midazolam $(1 \mathrm{mg})$, and fentanyl $(50 \mu \mathrm{g})$ were used with incremental boluses for sedation when needed for rescue sedation and analgesia in case the patient reported pain or anxiety and the total doses were documented. Invasive blood pressure monitoring was applied after sedation was commenced. The level of sedation was monitored with BIS and an Observers Assessment of Alertness/Sedation Scale (OAA/S). The sedative doses were adjusted in response to changes in the OAA/S score (target score: $\geq 3$ ) and BIS values (target value: 65-85) as well as the hemodynamic variables and patient response to verbal stimuli. The patient's response to verbal stimuli was used as the primary sedation target.

The scalp block was performed as previously described by Girvin [4]. Bupivacaine $0.25 \%$ was used for the nerve blocks. Bupivacaine was 1:1 diluted with saline and epinephrine $1 / 200000$ was added to the mixture. The local anesthetic mixture was divided in $5 \mathrm{~mL}$ syringes and the blocks were performed with these. Rescue lidocaine $1 \%$ was used for scalp infiltration in case of insufficient analgesia.

After initial experience we observed discomfort during surgery related to osteoarthritic pain. Bilateral SCPB was added to the regional anesthesia technique for patients with cervical osteoarthritic pain and position related pain. SCPB was performed at the posterior border of the sternocleidomastoid muscle; $5 \mathrm{~mL} 0.25 \%$ bupivacaine was injected from cephalad to caudal directions. A maximum bupivacaine dose $\left(2 \mathrm{mg} \mathrm{kg}^{-1}\right)$ was determined for each patient to use in all blocks and the maximum dose was not exceeded. Total doses of local anesthetics were recorded at the end of the procedure.

Sedation was discontinued 10-20 min before macrostimulation and the microelectrode recordings (MERs). Time to emergence was defined as the time elapsed from the discontinuation of the sedative infusion to the time the patients were able to cooperate with macro stimulation. Patients were also monitored for intraoperative adverse events and complications including upper airway obstruction, respiratory insufficiency, intraoperative hypertension, and pain complaints, restlessness, impaired cognition, and lack of cooperation, anxiety, voluntary or involuntary movements, seizures, and dyskinesia. The total duration of the procedure
TABLE 1: Patient characteristics, procedural duration, and emergence time.

\begin{tabular}{lc}
\hline Gender F/M $(n)$ & $14 / 11$ \\
Age $(\mathrm{yr})$ & $54.45(10.39)$ \\
Weight $(\mathrm{kg})$ & $68.66(4.32)$ \\
$\mathrm{BMI}\left(\mathrm{kg} / \mathrm{m}^{2}\right)$ & $25.29(5.50)$ \\
Procedure duration $(\mathrm{min})$ & $323.75(64.53)$ \\
Emergence time (min) & $19.61(19.94)$ \\
$\begin{array}{l}\text { Duration of MER and } \\
\text { macrostimulation (one side) } \\
\text { (min) }\end{array}$ & $27.69(20.06)$ \\
$\begin{array}{l}\text { Duration of MER and } \\
\text { macrostimulation (other side) } \\
\text { (min) }\end{array}$ & \\
\hline
\end{tabular}

BMI: body mass index; MER: microelectrode recordings.

Values are mean (standard deviation) and numbers.

included initial sedation, performance of regional anesthesia, stereotactic frame insertion, stereotactic CT/MRI Image Fusion, MERs, macrostimulation, and closure.

At the end of the procedure patients were transferred to the postanesthesia care unit (PACU). Postoperative pain was evaluated in the PACU at arrival and then at 1, 6, 12, and $24 \mathrm{~h}$ using a $0-10 \mathrm{~cm}$ verbal analogue scale (VAS) (zero: no pain, 10: maximal pain ever). Postoperative pain management consisted of $50 \mathrm{mg}$ tramadol every 8 hours.

Statistical analysis was performed with the Statistical Package for Social Sciences (SPSS) software version 18 (SPSS Inc., Chicago, IL, USA). Discrete categorical data are presented as numbers of occurrences $(n)$, percent (\%), and median; continuous data are given as mean (standard deviation: SD). Differences in demographic, surgical, anesthetic, and postoperative data were tested with Student's $t$ test (continuous data) or by Pearson's $\chi^{2}$ test and Fisher's exact test as appropriate (categorical data). A $P$ value 0.05 was considered significant.

\section{Results}

During the study period 26 patients with PD were scheduled for DBS of the subthalamic nucleus (STN). In one patient surgery was cancelled due to preoperative uncontrolled hypertension.

There were 11 males (41.7\%) and 14 females (58.3\%). There was an age difference between two genders [males 46 (10.12) years and females 59.64 (6.92) years, resp., $P=0.001]$ (Table 1). Hemodynamic parameters were within $\pm 20 \%$ of baseline values except in 4 patients. These patients experienced hypertension and it was treated either with either nitroglycerine $\left(0.1 \mu \mathrm{g} \mathrm{kg}^{-1} \mathrm{~h}^{-1}\right)$ or esmolol $\left(0.5-0.1 \mu \mathrm{g} \mathrm{kg}^{-1} \mathrm{~h}^{-1}\right)$ infusions. Tachycardia was observed in 2 patients; these two patients also received an esmolol infusion (Tables 2 and 3).

All patients were able to complete the procedure with the planned anesthesia technique; there was no conversion to general anesthesia. Dexmedetomidine, propofol, and bupivacaine were used in all patients. The mean total 
TABLE 2: Hemodynamic, respiratory variables and sedation levels during specific procedures.

\begin{tabular}{lccccc}
\hline & HR $\left(\right.$ beat $\left.\mathrm{min}^{-1}\right)$ & $\mathrm{MAP}(\mathrm{mmHg})$ & $\mathrm{BIS}$ & $\mathrm{SpO}_{2}(\%)$ & $\mathrm{RR}^{\left(\mathrm{rate} \mathrm{min}^{-1}\right)}$ \\
\hline Baseline & $81.13(10.68)^{*}$ & $102.36(19.41)^{*}$ & $96.15(3.07)$ & $96.40(2.68)$ & $14.32(1.06)$ \\
Initial sedation & $73.47(11.42)$ & $90.52(15.05)$ & $69.80(5.13)$ & $97.21(2.08)$ & $13.13(0.5)$ \\
Stereotactic frame & $76.30(8.28)$ & $87.04(14.51)$ & $71.92(5.36)$ & $97.54(1.53)$ & $13.83(1.27)$ \\
CT imaging & $75.00(9.29)$ & $86.04(11.55)$ & $87.76(8.76)$ & $98.21(1.56)$ & $13.13(0.53)$ \\
Skin incision & $74.54(8.00)$ & $87.59(12.37)$ & $87.76(8.76)$ & $98.47(1.69)$ & $13.13(0.53)$ \\
MER (one side) & $67.39(9.27)$ & $81.30(12.62)$ & $76.5(10.09)$ & $96.86(5.19)$ & $13.00(0.78)$ \\
Macrostimulation (one side) & $68.04(7.49)$ & $81.91(10.05)$ & $85.90(6.11)$ & $98.34(1.84)$ & $12.46(0.93)$ \\
MER (other side) & $63.26(8.99)$ & $76.82(12.51)$ & $80.27(9.34)$ & $98.95(1.33)$ & $13.13(0.53)$ \\
Macrostimulation (other side) & $65.21(11.22)$ & $77.21(13.27)$ & $87.27(5.72)$ & $98.86(1.51)$ & $13.58(1.06)$ \\
Closure & $68.69(8.55)$ & $79.00(9.96)$ & $85.60(9.37)$ & $98.78(1.50)$ & $13.13(0.53)$ \\
PACU & $68.04(7.49)$ & $81.91(10.05)$ & $85.90(6.11)$ & $98.34(1.84)$ & $12.46(0.93)$ \\
\hline
\end{tabular}

HR: heart rate, MAP: mean arterial pressure, BIS: bispectral index, $\mathrm{SpO}_{2}$ : peripheral oxygen saturation, RR: respiratory rate, CT: computerized tomography, MER: microelectrode recordings, and PACU: post anesthesia care unit. Values are mean (SD), ${ }^{*}$ significant difference between baseline HR, MAP and all other measurements.

TABLE 3: The doses of the sedatives, local anesthetics, and hypotensive agents.

\begin{tabular}{lcc}
\hline & $n$ & Mean (SD) \\
\hline $\begin{array}{l}\text { Dexmedetomidine } \\
\quad \text { Loading dose }\left(\mu \mathrm{g} \mathrm{kg}^{-1}\right)\end{array}$ & 25 & $62.14(9.89)$ \\
$\quad$ Infusion rate $\left(\mu \mathrm{g} \mathrm{kg}^{-1} \mathrm{~h}^{-1}\right)$ & & $0.26(0.21)$ \\
$\quad$ Total dose $(\mu \mathrm{g})$ & & $154.78(64.65)$ \\
Propofol & & \\
$\quad$ Dose $\left(\mathrm{mg} \mathrm{kg}^{-1}\right)$ & 25 & $1.68(0.84)$ \\
$\quad$ Total dose $(\mathrm{mg})$ & & $2(0.5)$ \\
$\begin{array}{l}\text { Midazolam } \\
\quad \text { Total dose }(\mathrm{mg})\end{array}$ & 4 & $100(0.25)$ \\
Fentanyl & & \\
$\quad$ Total dose $(\mu \mathrm{g})$ & 10 & $89.75(20.89)$ \\
Bupivacaine & & \\
$\quad$ Total dose $(\mathrm{mg})$ & 25 & $90(70.7)$ \\
Lidocaine & & \\
$\quad$ Total dose $(\mathrm{mg})$ & 2 & $0.05(0.01)$ \\
Esmolol \\
$\quad$ Infusion $\left(\mathrm{mg} \mathrm{kg}{ }^{-1} \mathrm{~min}^{-1}\right)$
\end{tabular}

Values are mean (standard deviation).

dexmedetomidine loading dose was 62.14 (9.89) $\mu$ g. During the procedure the mean dexmedetomidine infusion rate was $0.26(0.21) \mu \mathrm{g} \mathrm{kg}^{-1} \mathrm{~h}^{-1}$. The mean total dexmedetomidine dose was 154.78 (64.68) $\mu \mathrm{g}$. Rescue propofol, midazolam, and fentanyl were only used during the regional anesthesia performance with incremental dosing. The mean propofol dose was $1.68(0.84) \mathrm{mg} \mathrm{kg}^{-1}$ and the mean total dose was $117.72(59.11) \mathrm{mg}$, the maximum fentanyl dose was $100 \mu \mathrm{g}(n=$ $10)$, and the maximum midazolam dose was $2 \mathrm{mg}(n=4)$ (Table 3).

Patients were calm and responding to verbal commands throughout the procedure. The OAA/S score varied between
TABLE 4: Intraoperative adverse events.

\begin{tabular}{lll}
\hline & & $n$ \\
\hline Cardiovascular & Intra operative hypertension & 4 \\
& Pitosis & 2 \\
Regional anaesthesia & Eye lid hematoma & 1 \\
& Insufficient analgesia additional & 2 \\
& lidocaine infiltration & 2 \\
Discomfort & Restless leg complaints & 0 \\
Airway, respiratory & & 2 \\
Neurologic & Dyskinesia & 0 \\
Emergence delay & & \\
\hline
\end{tabular}

Values are numbers of occurrences.

2 and 5 and the mean lowest OAA/S score was 3 . Bradycardia and hypotension were not observed; there was no need to adjust he sedative doses according to alterations in the hemodynamic variables. The mean BIS values were 69 during the performance of regional anesthesia and 85 during the rest of the procedure. During the neurophysiologic testing the mean BIS value was 85 . The neuronal discharges from the target nuclei were not suppressed and the neurophysiologist was able to localize the STN successfully. After successful MERs were obtained clinical macrostimulation was commenced. The mean time to emergence and cooperation with clinical macrostimulation was 19.35 (17.85) min. The ability to cooperate with macro stimulation was delayed in two patients (55 min and $75 \mathrm{~min}$ ). Bradycardia and hypotension were not observed; there was no need to adjust the sedative doses according to alterations in the hemodynamic variables. The mean total fluid administered was 1513.09 (531.95) $\mathrm{mL}$. Anesthesia related adverse events were minor (Table 4). None of them were concerning the airway or respiration.

Mean VAS pain scores were 0 at the first and sixth hour measurements and 4 at 12 and 24 hours postoperatively. 


\section{Discussion}

This study demonstrated that dexmedetomidine sedation and regional anesthesia with scalp block and SCPB provided satisfactory surgical conditions and pain relief in patients undergoing DBS for the treatment of movement disorders in PD. We used dexmedetomidine with a loading dose $\left(1 \mu \mathrm{g} \mathrm{kg}^{-1} 10 \mathrm{~min}^{-1}\right)$ followed by a low dose infusion $\left(0.26 \mu \mathrm{g} \mathrm{kg}^{-1} \mathrm{~h}^{-1}\right)$ and discontinued the infusion well before the neurologic evaluation and we observed that this method does not interfere with neurophysiologic testing. Although hypertension requiring antihypertensive therapy was observed, anesthesia related adverse events were minor.

4.1. Sedation. During functional neurosurgery, specific brain structures are detected by their unique neuronal firing [2]. The effects of anesthetic agents on MERs are inconclusive. Anesthetics can alter neuronal firing frequency and impair patient assessment [5]. It is not clear which anesthetic allows the most effective MERs [2]. General anesthesia decreases the background of STN MERs [6]. Propofol and midazolam are anesthetics agents that potentiate the effects of Gammaaminobutyric acid, an inhibitor neurotransmitter, and thus they can alleviate tremor and interfere with brain mapping [2]. However a recent published study showed that propofol and fentanyl did not cause any difficulty in identifying MER signal characteristics of STN [7]. Dexmedetomidine is an alpha-2 agonist with analgesic properties, provides clinically stable blood pressure, and unlike the other sedatives does not affect the cerebral cortex. Dexmedetomidine produces a state of sedation similar to physiological sleep without respiratory depression which is unique in neurosurgical patients $[8,9]$. The ideal sedative utilization of dexmedetomidine during DBS is not clear. Several studies showed successful MERs with dexmedetomidine sedation. While low dose infusions of dexmedetomidine $\left(0.1 \mu \mathrm{g} \mathrm{kg}^{-1} \mathrm{~h}^{-1}\right)$ have no effect on the STN neuronal discharges, higher rates $\left(0.5 \mu \mathrm{g} \mathrm{kg}^{-1} \mathrm{~h}^{-1}\right)$ have been reported to suppress the neuronal firing in the STN [9]. The application of a loading dose is controversial. It was reported that a loading dose of $0.5-1 \mu \mathrm{g} \mathrm{kg}^{-1}$ did not interfere with the surgical procedure or MER [10]. Other investigators found a loading dose unnecessary and suggested that dexmedetomidine at infusion rates of 0.1 to $0.4 \mu \mathrm{g} \mathrm{kg}^{-1} \mathrm{~h}^{-1}$ titrated to maintain BIS values $>80$ are appropriate in this setting [11].

The STN was stimulated in our patients and dexmedetomidine was used as the main sedative. All patients received a loading dose. The mean dexmedetomidine doses $\left(0.26 \mu \mathrm{g} \mathrm{kg}^{-1} \mathrm{~h}^{-1}\right)$ were similar to previous reports $[12,13]$. The highest dexmedetomidine infusion rate was $1.03 \mu \mathrm{g} \mathrm{kg}^{-1} \mathrm{~h}^{-1}$ in one patient during maintenance of anesthesia. The dexmedetomidine infusion was discontinued before the neurophysiologic testing. During the neurophysiologic testing the BIS values showed an alert state (mean 85). We suggest that a loading dose does not lead to alterations in neuronal firing frequencies provided that the dexmedetomidine infusion is discontinued before neurophysiologic testing and an alert state is ensured; furthermore the loading dose is required to provide patient comfort throughout the performance of regional anesthesia. We used propofol midazolam and fentanyl only during the performance of the nerve blocks with incremental boluses and the patients did not receive these agents during the recordings; thus we cannot comment on the effects of these agents on MERs.

Dexmedetomidine produces sedation by its action on the alpha-2 receptors in the locus caeruleus-not in the cerebral cortex-and it is not clear whether BIS monitorization is the best method to assess this sedation. Depressed MERs associated with BIS values $<80$ and an intraindividual and interindividual variability of the BIS values in sedated subjects have been reported; we observed that the BIS scores and sedation scores were correlated $[11,14]$. According to our results during dexmedetomidine sedation the time required for awakening and cooperation with the neurologic examination was approximately 19 minutes. This result is in accordance with previous reports [13]. Dexmedetomidine can also cause somnolence and the patients may not be apprehensive during awake craniotomy [12]. Awakening times up to 48 minutes have been reported [15]. In the presenting study time to neurologic examination was delayed in two patients. These two patients were arousable though the clinical testing was delayed due to dyskinesia. The reason for dyskinesia is not clear; however an association between propofol and dyskinesia has been reported earlier [16].

4.2. Regional Anesthesia. After initial experience we observed that the patients complained of having pain during the procedure despite adequate surgical analgesia. Pain complaints were related to the positioning of the head and neck. These patients had difficulty to tolerate the procedure after 1 hour. Self-reported physical pain and psychological suffering during DBS were previously reported [17]. Patients with PD can have musculoskeletal and osteoarthritic pain [18]. The preprocedural cessation of all medications and the fixation of the head to the stereotactic frame during the procedure can aggravate pain [17]. We avoided analgesia with opioids due to the risk of respiratory depression. The use of preventive SCPB for postoperative cervicocephalic pain in neurosurgery was previously reported [19]. We added the SCPB in the regional anesthesia technique for the relief of pain related to prolonged fixed neck position and pain due to cervical osteoarthritis. The neck pain problem was resolved thereafter. There were two patients in the series that had complaints of restless leg; this is a sleep disorder and the frequency of restless leg syndrome in PD was reported up to 21.9\% [20]. To our opinion musculoskeletal pain and restless leg syndrome should be considered as a difficulty for conscious sedation.

4.3. Adverse Events. Hypertension is a common intraoperative problem during DBS. We observed hypertension in 4 patients; this was successfully treated with esmolol and nitroglycerine. The use of dexmedetomidine as a sedative agent is associated with a risk of bradycardia in elderly patients especially when a loading dose is used and at higher infusion rates $\left(0.7 \mu \mathrm{g} \mathrm{kg}^{-1} \mathrm{~min}^{-1}\right)$ [21]. Although we did use a loading dose we did not observe any significant bradycardia; 
this may be related to the fact that our infusion dose was not high and that our patients were not critically ill patients as reported in some previous studies.

Other complications related to the anesthesia methods were minor. One patient developed eyelid hematoma during nerve blockade. One patient developed eyelid hematoma during nerve blockade and we observed pitosis in two patients after the removal of the surgical dressing. Both complications had a benign progress with no further sequelae. We considered that the pitosis was either related to the supraorbital nerve blockade or to the compression of the same nerve by the head pin.

4.4. Postoperative Pain. Postoperative pain scores were low. The intraoperative use of dexmedetomidine may have improved analgesia [22]. We suggest that the regional anesthesia technique provided $12 \mathrm{~h}$ analgesia and the SCPB may have contributions to postoperative analgesia.

This is not a comparative study, which is a limitation; however the obtained data and the consequent analysis and the derived conclusions can contribute to the existing literature and provide a rationale for a randomized controlled trial to investigate the role of SCPB in the setting of conscious sedation for DBS.

\section{Conclusions}

Conscious sedation with dexmedetomidine and regional anesthesia with scalp block and SCPB provided good surgical conditions, patient comfort, and analgesia without interfering with neurophysiological testing during DBS in PD. We suggest that during DBS the implementation of the SCPB may be useful for patients with osteoarthritic cervical pain.

\section{Conflict of Interests}

The authors report no conflict of interests in this paper.

\section{References}

[1] L. Venkatraghavan, M. Luciano, and P. Manninen, "Anesthetic management of patients undergoing deep brain stimulator insertion," Anesthesia \& Analgesia, vol. 110, no. 4, pp. 1138-1145, 2010.

[2] C. C. M. Poon and M. G. Irwin, "Anaesthesia for deep brain stimulation and in patients with implanted neurostimulator devices," British Journal of Anaesthesia, vol. 103, no. 2, pp. 152165, 2009.

[3] E. Chevrier, V. Fraix, P. Krack, S. Chabardes, A.-L. Benabid, and P. Pollak, "Is there a role for physiotherapy during deep brain stimulation surgery in patients with Parkinson's disease?" European Journal of Neurology, vol. 13, no. 5, pp. 496-498, 2006.

[4] J. P. Girvin, "Neurosurgical considerations and general methods for craniotomy under local anesthesia," International Anesthesiology Clinics, vol. 24, no. 3, pp. 89-114, 1986.

[5] D. N. Ruskin, D. A. Bergstrom, Y. Kaneoke, B. N. Patel, M. J. Twery, and J. R. Walters, "Multisecond oscillations in firing rate in the basal ganglia: robust modulation by dopamine receptor activation and anesthesia," Journal of Neurophysiology, vol. 81, no. 5, pp. 2046-2055, 1999.

[6] F. Hertel, M. Züchner, I. Weimar et al., "Implantation of electrodes for deep brain stimulation of the subthalamic nucleus in advanced Parkinson's disease with the aid of intraoperative microrecording under general anesthesia," Neurosurgery, vol. 59, no. 5, Article ID E1138, 2006.

[7] W. Kim, I. H. Song, Y. H. Lim et al., "Influence of propofol and fentanyl on deep brain stimulation of the subthalamic nucleus," Journal of Korean Medical Science, vol. 29, pp. 1278-1286, 2014.

[8] K. M. Ho, "Is dexmedetomidine an ideal sedative agent for neurosurgical patients?" Anaesthesia and Intensive Care Journal, vol. 40, pp. 927-928, 2012.

[9] T. Wang, S. Ge, W. Xiong, P. Zhou, J. Cang, and Z. Xue, "Effects of different loading doses of dexmedetomidine on bispectral index under stepwise propofol target-controlled infusion," Pharmacology, vol. 91, no. 1-2, pp. 1-6, 2013.

[10] M. Sassi, E. Zekaj, A. Grotta et al., "Safety in the use of dexmedetomidine (precedex) for deep brain stimulation surgery: our experience in 23 randomized patients," Neuromodulation, vol. 16, no. 5, pp. 401-406, 2013.

[11] W. J. Elias, M. E. Durieux, D. Huss, and R. C. Frysinger, "Dexmedetomidine and arousal affect subthalamic neurons," Movement Disorders, vol. 23, no. 9, pp. 1317-1320, 2008.

[12] A. N. de Almeida, C. Tavares, A. Tibano, S. Sasaki, K. N. Murata, and R. Marino Jr., "Dexmedetomidine for awake craniotomy without laryngeal mask," Arquivos de Neuro-Psiquiatria, vol. 63, no. 3, pp. 748-750, 2005.

[13] M. J. Souter, I. Rozet, J. G. Ojemann et al., "Dexmedetomidine sedation during awake craniotomy for seizure resection: effects on electrocorticography," Journal of Neurosurgical Anesthesiology, vol. 19, no. 1, pp. 38-44, 2007.

[14] M. Haenggi, H. Ypparila-Wolters, K. Hauser et al., "Intra-and inter-individual variation of BIS-index and entropy during controlled sedation with midazolam/remifentanil and dexmedetomidine/remifentanil in healthy volunteers: an interventional study," Critical Care, vol. 13, article R20, 2009.

[15] C. Trombetta, A. Deogaonkar, M. Deogaonkar et al., "Delayed awakening in dystonia patients undergoing deep brain stimulation surgery," Journal of Clinical Neuroscience, vol. 17, no. 7, pp. 865-868, 2010.

[16] A. Deogaonkar, M. Deogaonkar, J. Y. K. Lee, Z. Ebrahim, and A. Schubert, "Propofol-induced dyskinesias controlled with dexmedetomidine during deep brain stimulation surgery," Anesthesiology, vol. 104, no. 6, pp. 1337-1339, 2006.

[17] R. Khatib, Z. Ebrahim, A. Rezai et al., "Perioperative events during deep brain stimulation: the experience at Cleveland Clinic," Journal of Neurosurgical Anesthesiology, vol. 20, no. 1, pp. 36-40, 2008.

[18] H. Oshima, Y. Katayama, T. Morishita et al., "Subthalamic nucleus stimulation for attenuation of pain related to Parkinson disease: clinical article," Journal of Neurosurgery, vol. 116, no. 1, pp. 99-106, 2012.

[19] K. Niijima and L. I. Malis, "Preventive superficial cervical plexus block for postoperative cervicocephalic pain in neurosurgery," Neurologia Medico-Chirurgica, vol. 33, no. 6, pp. 365-367, 1993.

[20] J. C. Gómez-Esteban, J. J. Zarranz, B. Tijero et al., "Restless legs syndrome in Parkinson's disease," Movement Disorders, vol. 22, no. 13, pp. 1912-1916, 2007. 
[21] J. A. Tan and K. M. Ho, "Use of dexmedetomidine as a sedative and analgesic agent in critically ill adult patients: a metaanalysis," Intensive Care Medicine, vol. 36, no. 6, pp. 926-939, 2010.

[22] G. Blaudszun, C. Lysakowski, N. Elia, and M. R. Tramèr, "Effect of perioperative systemic $\alpha 2$ agonists on postoperative morphine consumption and pain intensity: systematic review and meta-analysis of randomized controlled trials," Anesthesiology, vol. 116, no. 6, pp. 1312-1322, 2012. 


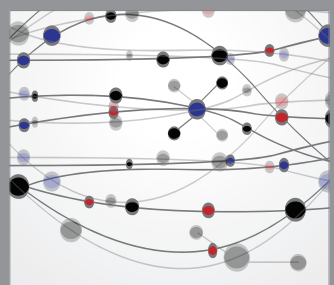

The Scientific World Journal
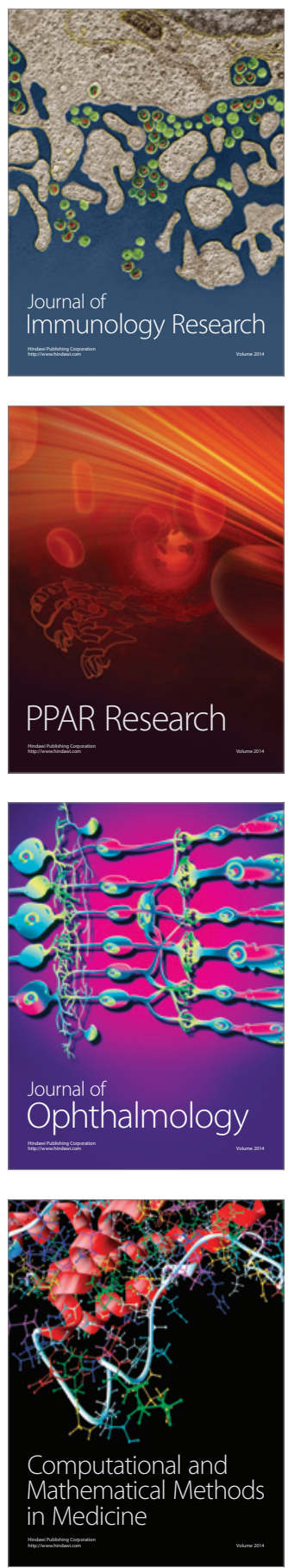

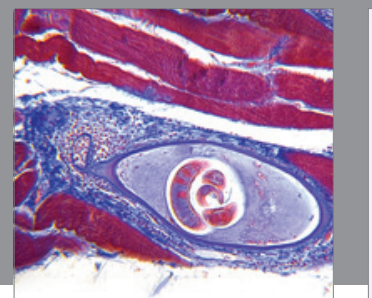

Gastroenterology

Research and Practice
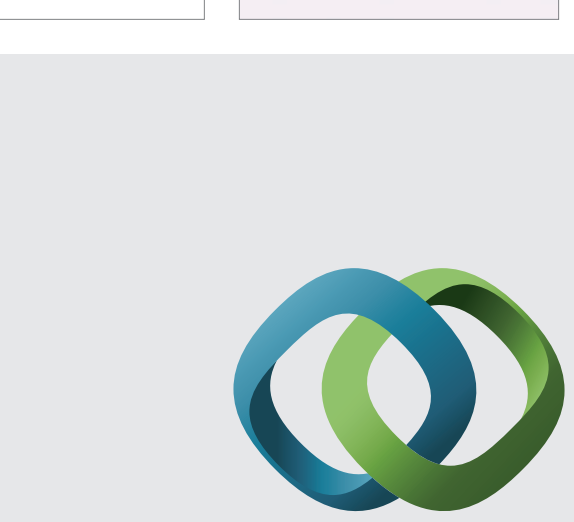

\section{Hindawi}

Submit your manuscripts at

http://www.hindawi.com
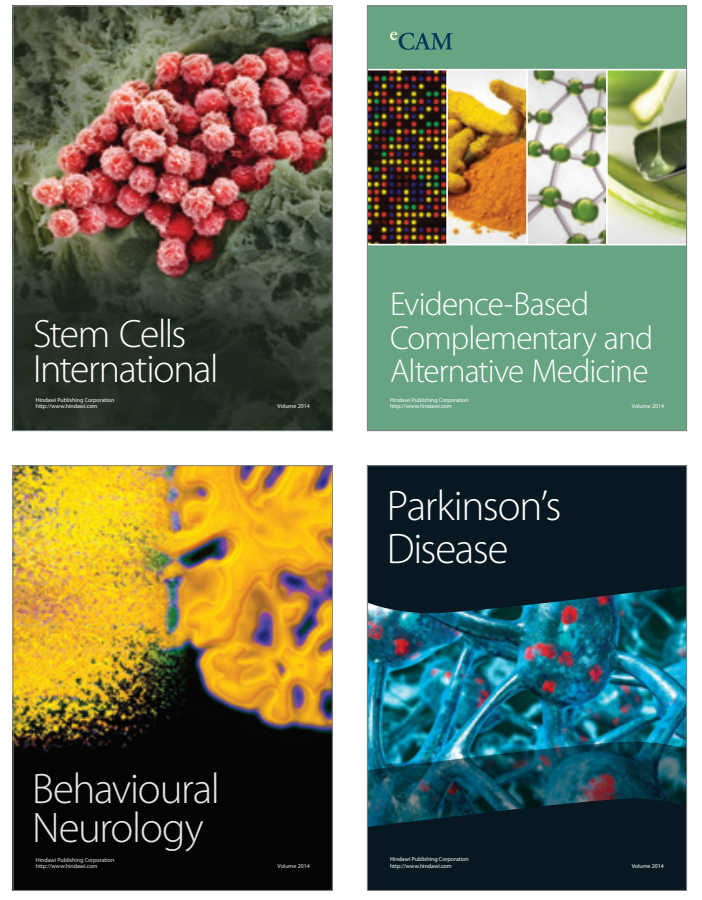
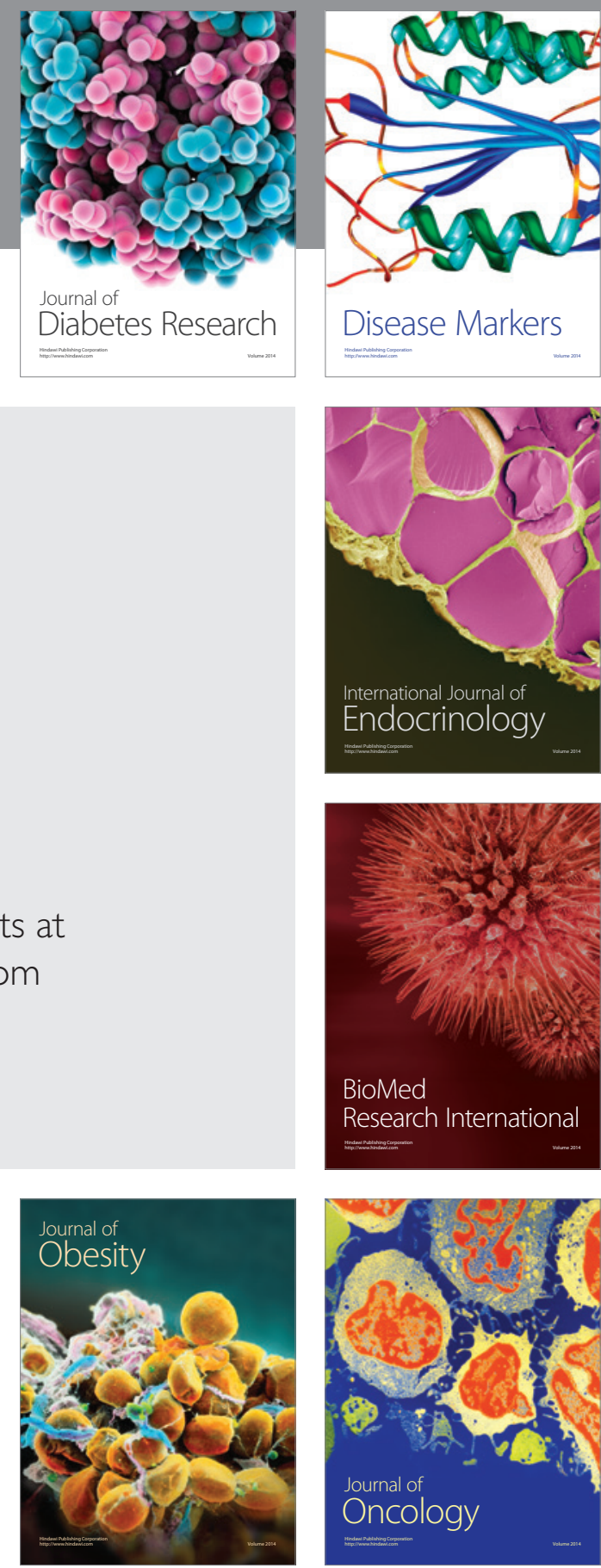

Disease Markers
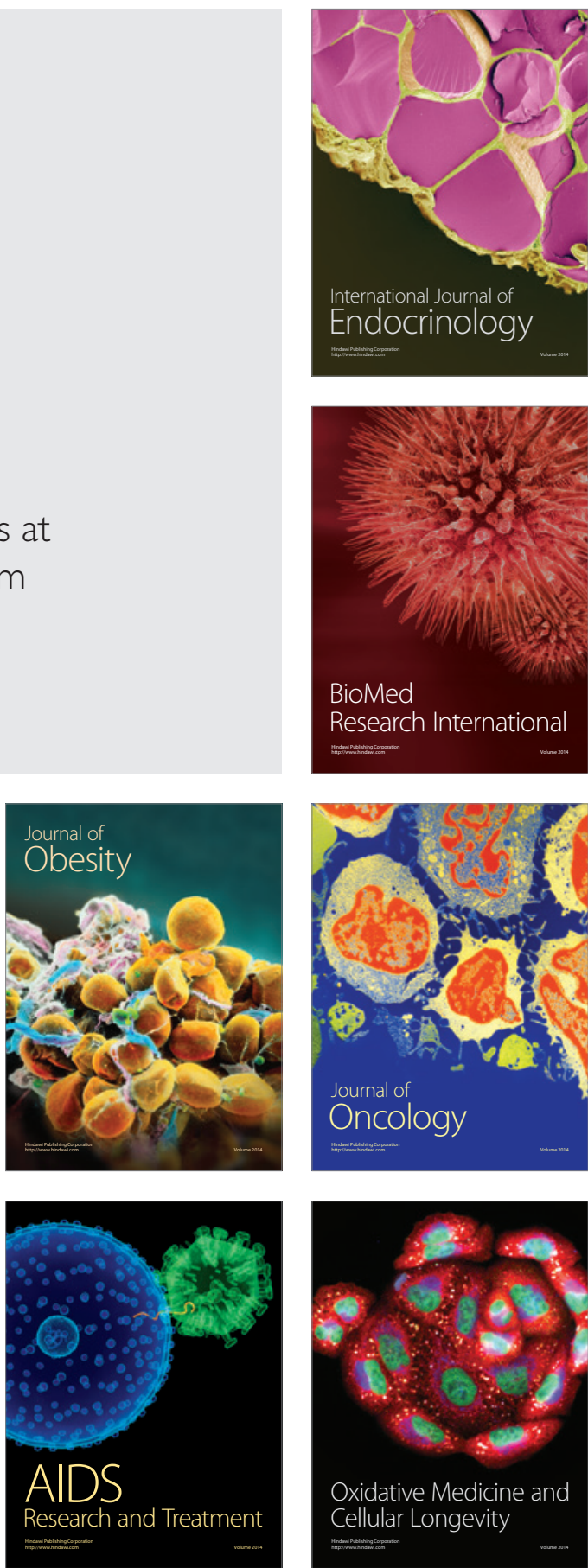